\title{
Contemporary Health Issues and Environmental Impact
}

\section{Edited by}

Dr. Mala Bose

Dr. Soma Aditya (Bandyopadhyay)

Department of Zoology

Sarojini Naidu College for Women

Dum Dum, Kolkata, West Bengal, India

Dr. Sandeep Poddar

Lincoln University College, Malaysia

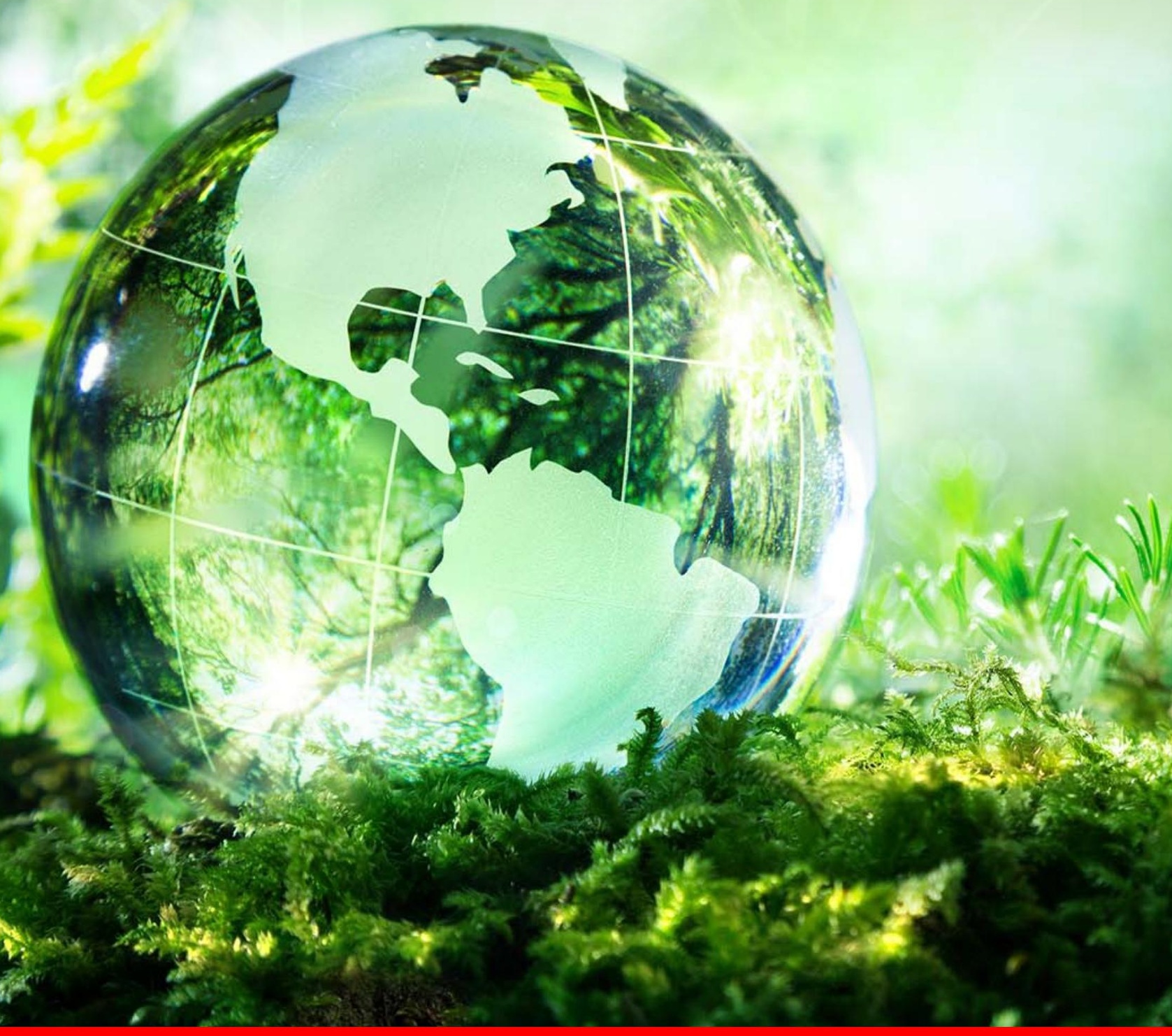

Published by :

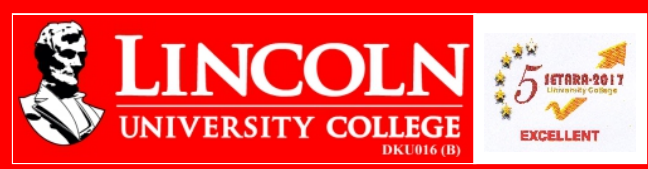


Contemporary Health Issues and Environmental Impact

\author{
Edited by \\ Dr. Mala Bose \\ Dr. Soma Aditya (Bandyopadhyay) \\ Department of Zoology \\ Sarojini Naidu College for Women \\ Dum Dum, Kolkata, West Bengal, India \\ Dr. Sandeep Poddar \\ Lincoln University College, Malaysia
}

PUBLISHED BY :

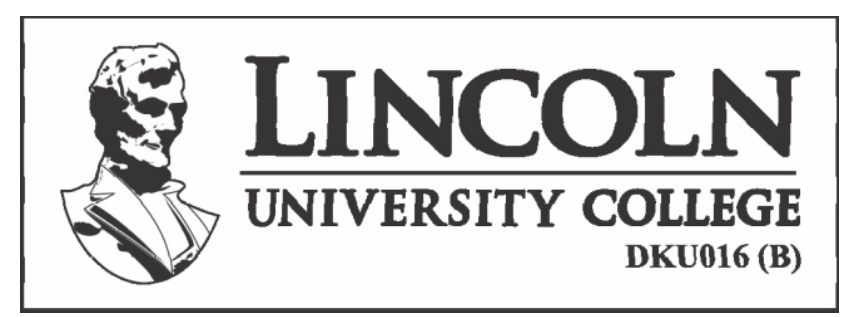


Copyright $\odot 2018$

Sarojini Naidu College, India \& Lincoln University College, Malaysia

All rights reserved

No part of this book can be reproduced or transmitted by any means, electronic or mechanical, including photocopying recording or by any information storage and retrieval system without prior written permission from the publisher.

Published by :

\section{LINCOLN UNIVERSITY COLLEGE Wisma}

Lincoln, No. 12, 14, 16 \& 18, Jalan SS

6/12,47301 Petaling Jaya, Selangor Darul

Ehsan, Malaysia. Tel.: +603-7806 3478,

Fax: +603-7806 3479Toll Free: 1-300-880-

111E-mail: info@lincoln.edu.my Web.:

www.lincoln.edu.my

ISBN : 978-967-10937-9-5 


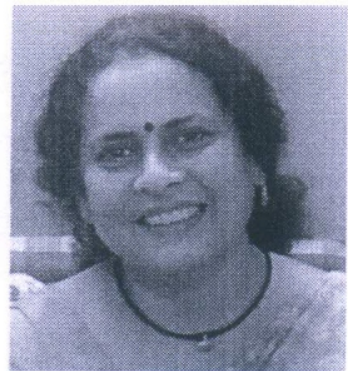

\section{From Organizing Secretary's desk}

A continuous interaction takes place between the constituent elements of nature and living organisms on earth. With an increasing use of our natural resources, environmental parameters are altered, which affects the living biota and human, in particular. Consequently, disease causing pathogens and parasites flourish at a greater rate resulting in increased incidence of diseases in human and domestic animals. Environmental changes facilitate the prevalence of vector-borne diseases like dengue, malaria, filariasis, and Japanese encephalitis, particularly in tropical countries like India. To address these issues related to human health, the "International Conference on Contemporary Health Issues and Environmental Impact" is being organized on 30th November, 2017 by the Department of Zoology, Sarojini Naidu College for Women. I hope this conference will provide an excellent platform for scientific deliberations and offer an opportunity to the scientists, academicians, teachers and students to update their knowledge and interact with their peers.

I take this opportunity to extend my warm appreciation to the invited speakers for their participation and contribution to the success of the conference. On behalf of the Organizing Committee, I would like to express our heartiest gratitude to our collaborators namely, Department of Zoology, WBSU, Barasat and Lincoln University College, Malaysia. We also thank West Bengal State Council of Higher Education for their financial support. We are grateful to Dr. Saibal Chatterjee, President of the Governing Body of our College and our Principal, Dr. Urmila Ukil for their constant support and encouragement. I am also thankful to my colleagues and staff of our college for their unstinted help and cooperation.

Last but not the least, I express my heartfelt greetings to all the teaching faculties and students of different colleges who have come to attend this conference. I hope this one day international conference will be of immense help to them. I wish them splendid memories of the conference.

Thank you all!

Kolkata

$23^{\text {rd }}$ November, 2017

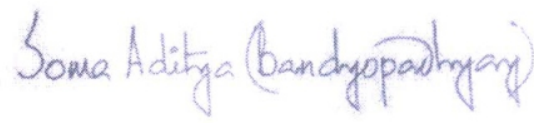

DR. SOMA ADITYA BANDYOPADHYAY 


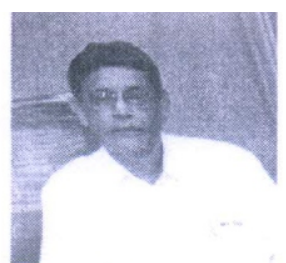

It is my pleasure to know that "International conference on contemporary health issues and environmental impact" is going to be held on 30th November, 2017 at Sarojini Naidu College for Women in collaboration with Deptt. of Zoology, West Bengal State University and Lincoin University, Malaysia. I am happy that in this conference participant including academicians, researchers will interact to prepare future policies on contemporary health issues and environmental impact.

The spectrums of health, environment and development hazards have been changed considerably over the millennia of human existence. In the past 50 years in particular, the world has seen considerable health gains. For example, childhood mortality and morbidity have been greatly reduced by better control and prevention of infectious diseases. People are living much longer. Between the 1950s and the 1990s, average life expectancy increased from 46 to 65 years, and the gap in life expectancy between rich and poor countries narrowed considerably, from 25 years in 1955 to 13.3 years in 1995.

The main health goal of governments and of WHO was declared in 1977, to be: "Attainment by all the people of the world by the year 2000 of a level of health that will permit them to lead a socially and economically productive life." However, various trends, including globalization of trade, travel and technology, urbanization and the growth of megacities, widening gaps between rich and poor, the continuing burden of infectious diseases, the rise in noncommunicable diseases, and growth in environmental threats, made a reassessment of this "Health for All" (HFA) strategy necessary in 1995.

There have been major advances in science and technology and health and medicine, infrastructure has expanded, literacy has increased, education has improved and incomes and opportunities have increased, especially for women. Yet, despite all this, in many instances the health gaps between and within countries are widening. Not all regions of the world have shared equally in improvements to health. Sub-saharan Africa, the world's poorest region, still has average life expectancies far below those of the wealthiest countries. Underlying much of this unequal burden of disease is the fact that environmental factors are a major contributor to sickness and death throughout the world, especially in the poorest regions.

Environmental illnesses are significantly more common among women than men. Their physiological differences make women particularly more vulnerable. Researchers suspect that there are a number of factors at work. One of the factors commonly linked with these conditions is the exposure to a growing number of toxic chemicals. Exposure to pollutants in air, water, soil, food and consumer products have been linked with cancer, damage to the reproductive system, respiratory and nervous systems and foetal abnormality. Further, in the developing nations, environmental and occupational problems are even more challenging due to inadequate technology, traditional and cottage industry level occupations and poor background health conditions.

It is essential to develop the information needed to design strategies for early detection and develop abatement methodologies. This international conference will provide an opportunity for scientists and policy analysts from both developed and developing countries to present the latest findings on important diseases and hazards and their implications for environmental and occupational health policy. Concerted follow-up efforts will sustain the momentum generated by the conference. This international gathering will surely address the challenges raised by ongoing climatic changes and its impact on human health, a common scientific platform has been provided to the academicians, scientists, researchers and UG/PG students to exchange their views and ideas. The major thrust areas of discussions are - allergy, dengue, cancer, asthma, diarrhea, adaptive evolution etc.

I wish a grand success of the International seminar be a meaningful.

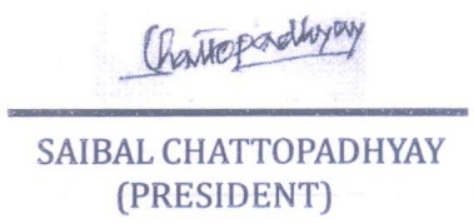




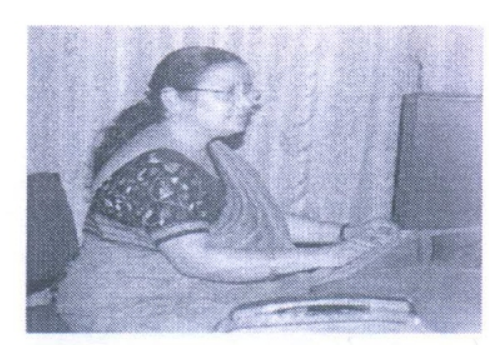

Message

I like to convey my heartiest congratulations to the organisers of the Department of Zoology for arranging the one day "International Conference on Contemporary Health Issues and Environmental Impact" organised in collaboration with the Department of Zoology, West Bengal State University, India and Lincoln University College, Malaysia with the financial assistance from West Bengal State Council of Higher Education to be held on $30^{\text {th }}$ November 2017 at Sarojini Naidu College for Women. I am wishing this academic event to be a grand success.

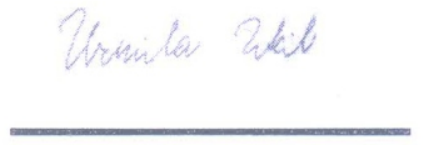

URMILA UKIL

(The Principal)

Sarojini Naidu College for Women 


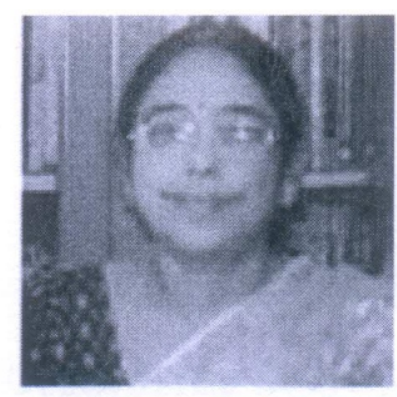

\section{Message from the Program Coordinator}

Since the last two to three decades, pathogens causing human diseases have increased in number and become a major threat to human health. Various forms of viral fever, gastrointestinal disorders, various carcinogens and allergens have posed a serious public health problem in countries of the South East Asia including India. Emerging vector borne diseases are also an important issues in global health and especially in tropical countries. Many endemic diseases have increased in incidence and many diseases are going to become endemic. Within few months dengue has claimed many lives in West Bengal especially in Kolkata and surrounding suburbs. An allergic reaction can be caused by any form of direct contact with allergen - eating, drinking, pollen, perfume, pet dander; dust etc. Today's stressful life style and environmental changes are the main causes of many of these diseases. Many of the people in our society are not aware of the above things. This conference is an attempt on our part to create a platform for open discussion among academicians, doctors, scientists, teachers and students about the health problems raised by climatic and life style changes. I hope the program will be successful in this regard and meet the expectations of our delegates.

Kolkata

$22^{\text {nd }}$ November, 2017

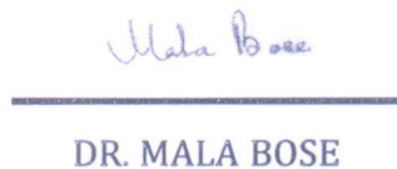




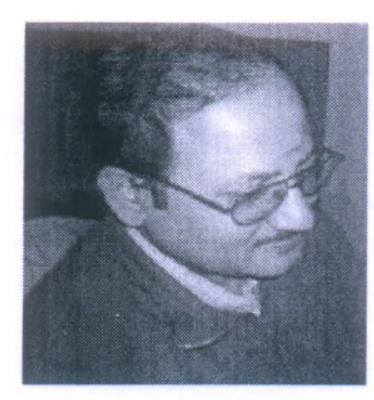

November 23, 2017

Message

It gives me immense pleasure to learn that the Department of Zoology of the Sarojini Naidu College for Women, Dum Dum, affiliated to the West Bengal State University, Barasat is going to organize an International Seminar on Contemporary Health Issues and Environmental Impact in association with the Department of Zoology of the University and Lincoln University College, Malayasia.

Environment and health are closely interlinked. Fine particulates in air, unacceptable carbon dioxide concentrations; photochemical smog; biodegradable, recalcitrant and presistent pollutants in water and soil; plastics and many such materials cause immense harm to health and environment. The problem has reached menacing proportion and it is necessary to address to the complex issues involved.

The seminar will consider the interrelationship between health and environment and it is expected that some solution will be recommended.

I wish the seminar all success.

PROF. BASAB CHAUDHURI

(VICE CHANCELLOR) 
Monocrotophos Resistance in Aulacophora foveicollis

Abhishek Mukherjee, Shubhanwita Basak and Smaranika Biswas

Metal toxicity in fishes: A Human Health Hazard

Adity Sarbajna

Arsenic toxicity through Dietary Intake pathways in the villages of West

Bengal, India: A Review

Damayanti Bakra

Leishmania donovanimurine peritoneal macrophage attachment

Induces parasite specific Protein Kinase C(PKC) - mediated

phosphorylated proteins

Debjani Das (Ghosh)

Impact of Climate Change on Parasitic Diseases: Do we need to bother?

Debraj Biswal

Brackish water Shrimp disease and its remedy by Maintaining water quality in the coastal belt of East Midnapur District West Bengal

Mayukhmala Mandal

Arsenic contamination in the lentic ecosystem and its environmental impact: Case study on some wetlands of Murshidabad

Santi Ranjan Dey and Mitu De

Protective potentials of Natrum Sulphuricum-200, a Homeopathic Remedy, against p-DAB induced Hepatocarcinogenesis in Mice

Nandini Bhattacharjee and_A.R. Khuda-Bukhsh

Climate Change and Aedes Mosquito Vector: A Projection towards

Future Scenario of Disease Transmission

Dipanwita Sarkar (Paria), Pratyush Ghosh and Susovan Sadhukhan

Seasonal disease occurrence, mortality and survival of adults and fingerlings of Channa punctatus (Bloch) by artificial inoculations of two strains of aeromonads

Rajarshi Ghosh and Sumit Homechaudhuri

Role of the 'Modern' Environment on Cancer

Subhadra Roy

Dietary Phytoestrogens - Boon or Bane?

Sudipta Majumdar (nee Paul)

Release of Urushiol from Mango peel due to Infestation by Fruit Borer Autocharis albizonalis leads to Contact Dermatitis

Tirthankar Dalui, Nabojit Mondal, Rupayan Rakshit 


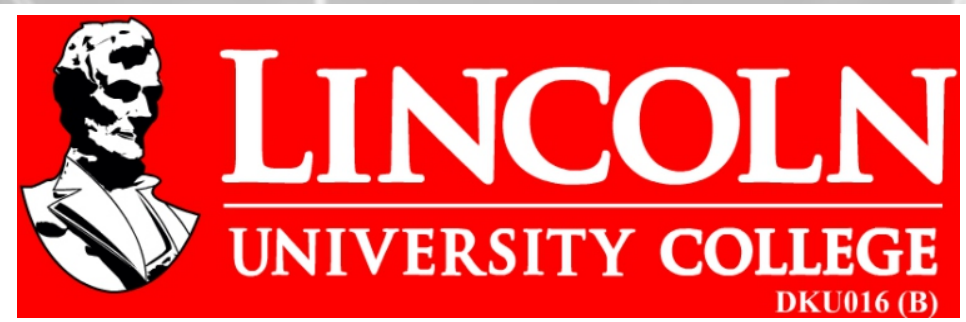

LINCOLN UNIVERSITY COLLEGE

Wisma Lincoln, No. 12, 14, 16 \& 18, Jalan SS 6/12,47301 Petaling Jaya, Selangor Darul Ehsan, Malaysia.

Tel.: +603-7806 3478Fax: +603-7806 3479

Toll Free: 1-300-880-111

E-mail: info@lincoln.edu.my Web.: www.lincoln.edu.my

Web.: www.lincoln.edu.my

ISBN : 978-967-10937-9-5

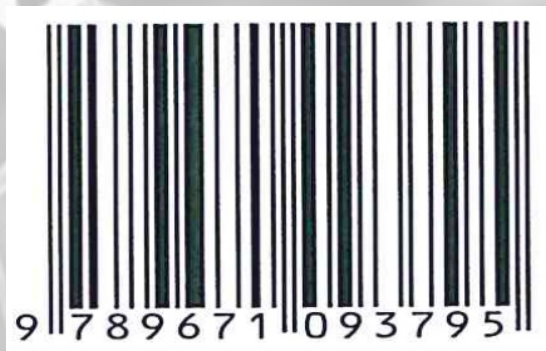

